تحفيز نمو أجنة بذور الليمون الحامض المحلي . Citrus limon L. Brum. خارج الجسم الحي

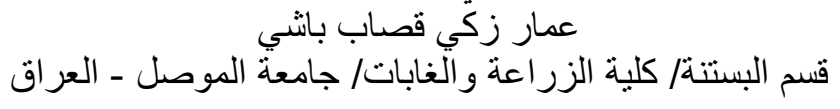

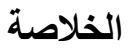

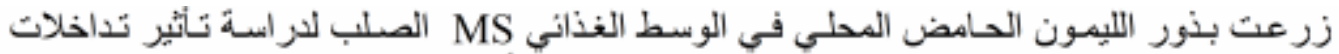
(kinetin+benzyladenine) Kin+BA

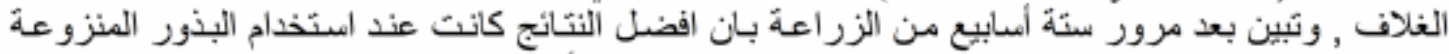

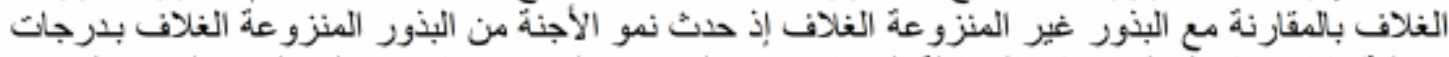

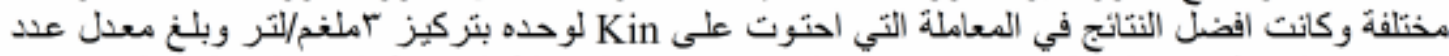

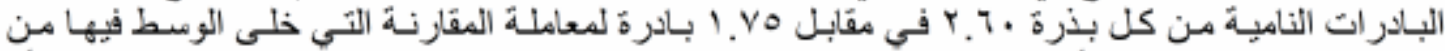

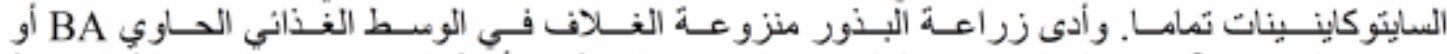

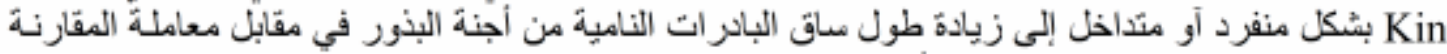

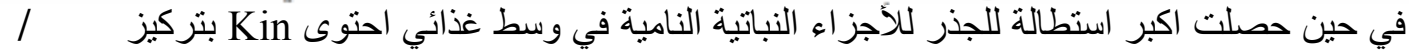

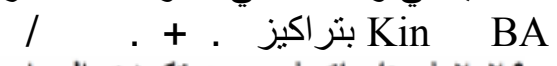

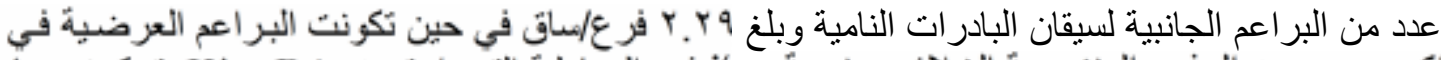

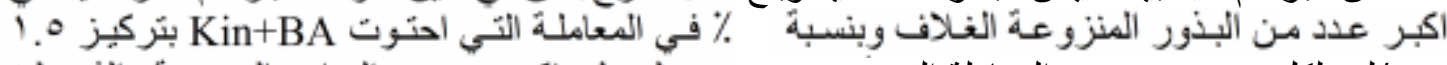

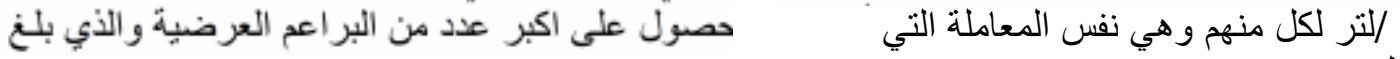

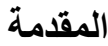

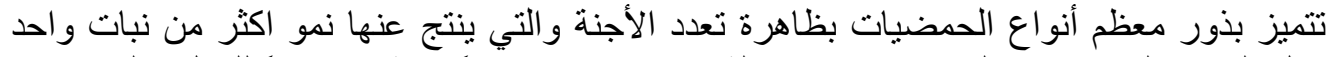

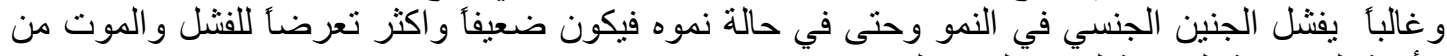

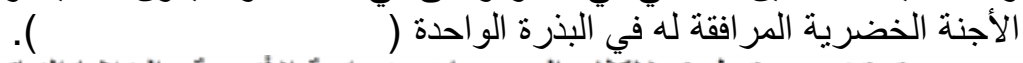

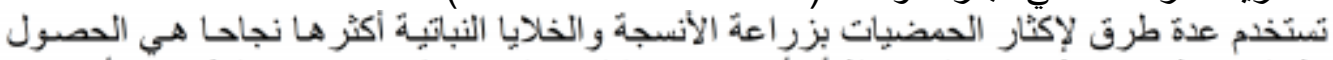

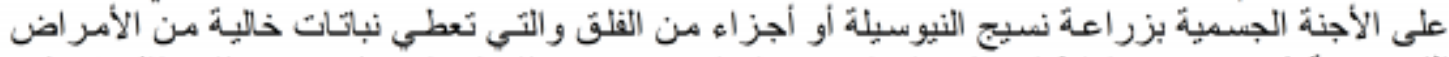

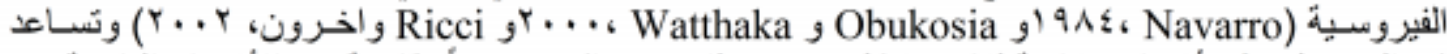

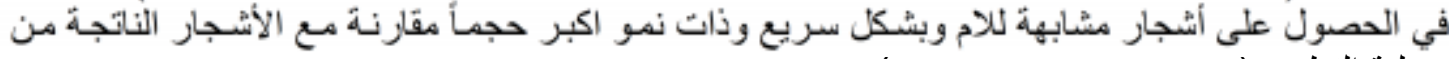

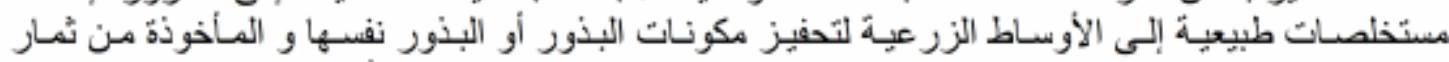

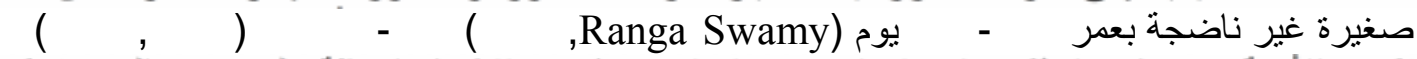

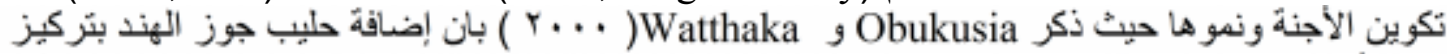

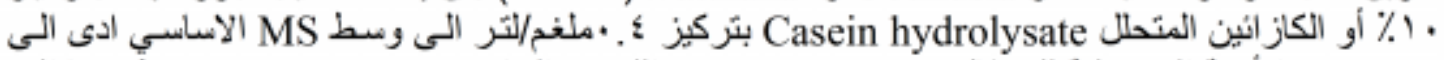

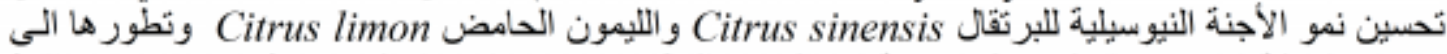

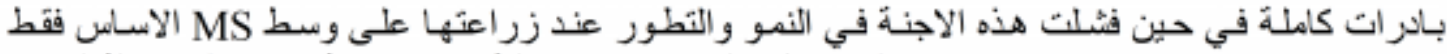

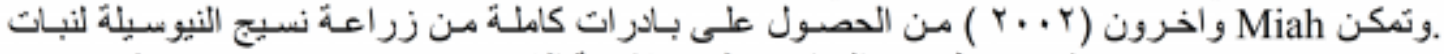

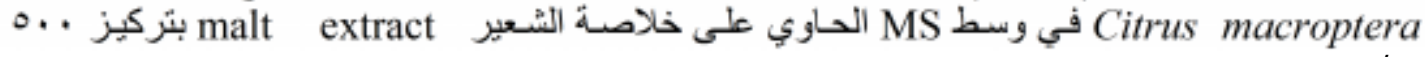

كن جهة اخرى تم الحصول على الاجنة الجمبية لنبـات الجوز الاغريقي

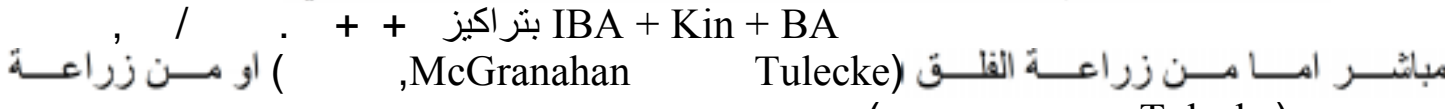
. . , Tulecke)

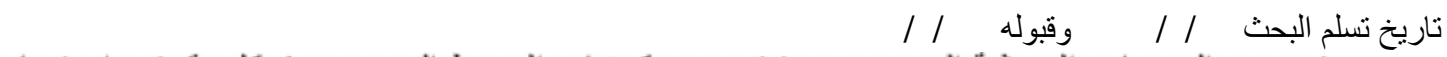

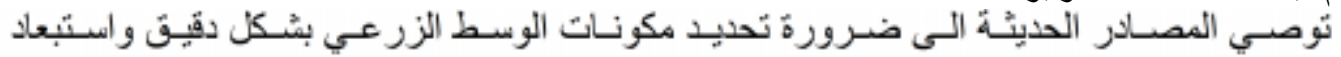

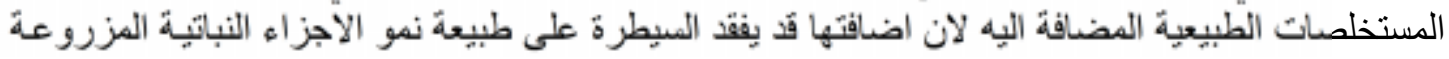

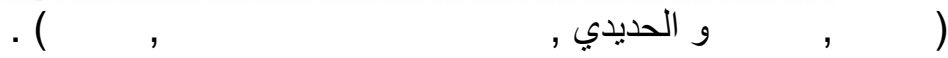




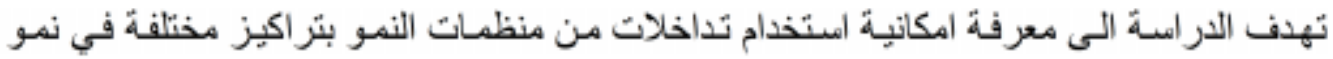

$$
\text { وتطور اجنة الليمون الحامض المحلي بديلا عن المستخلصات الطبيعية . }
$$

\section{مواد البحث وطرائقه}

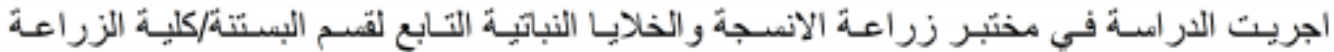

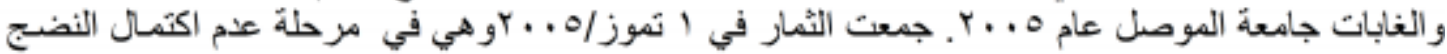

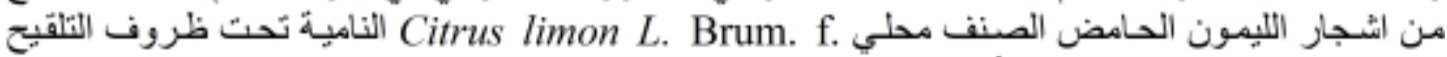

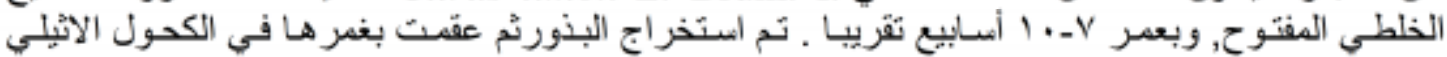

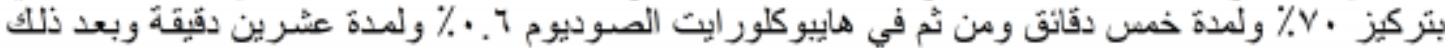

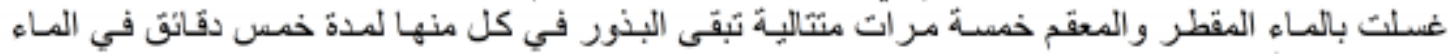
() Chandler Grosser)

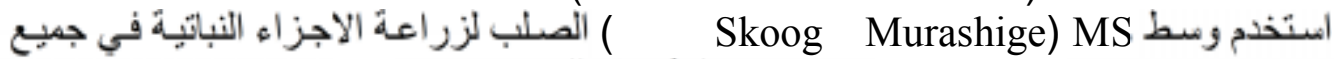

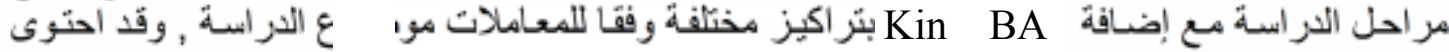

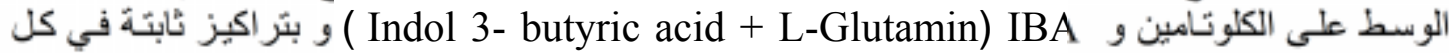
مل لكل قنينة وبعد ذلك عقم

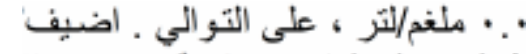

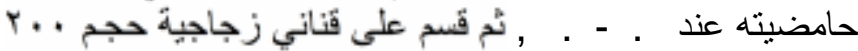

$$
\begin{aligned}
& \text { المدة عشرين دقبقة على درجة حرارة } \\
& \text { المعاملات التجريبية : }
\end{aligned}
$$

seed coat

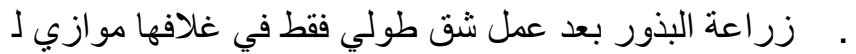

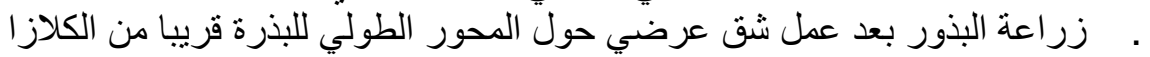

Kin+BA : ثانيا :

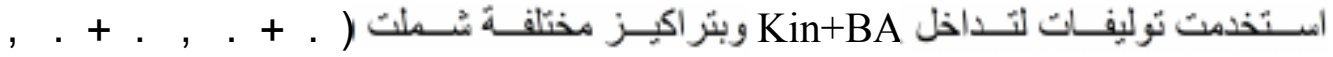

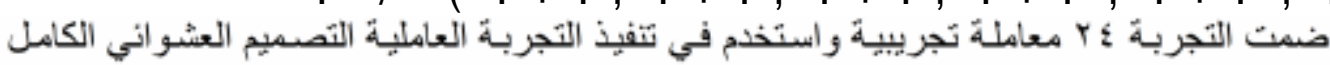

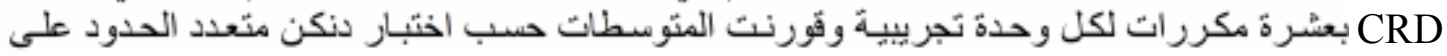

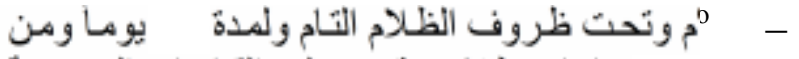

ساعات ظلام و قد سجلت القَاسـات النجريبية

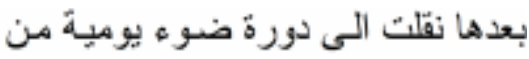

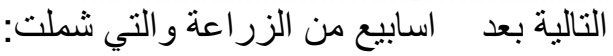

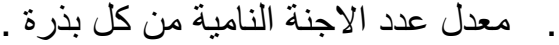

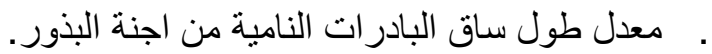

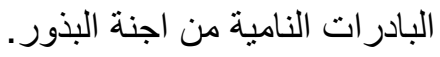

. معدل عدد الاوراق النامية على ساق البادرة.

. معدل عدد الفروع النامية على ساق البادرة البادية.

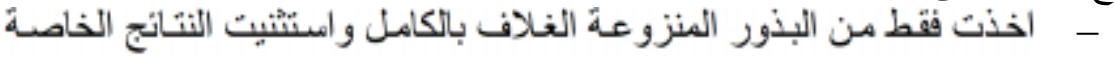

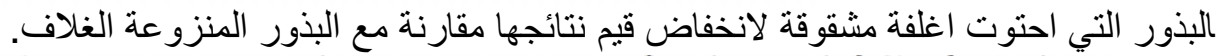

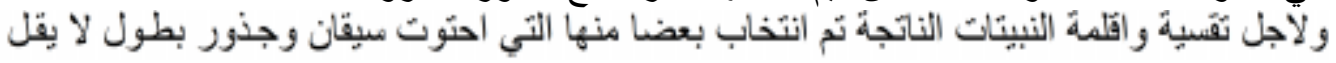

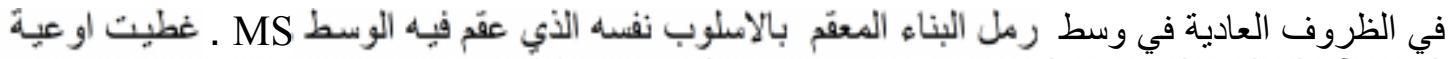

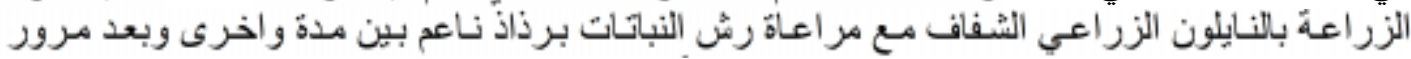

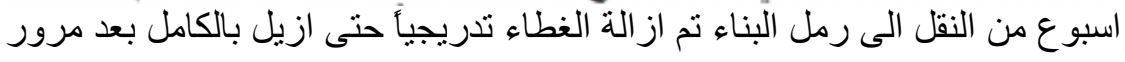




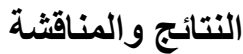

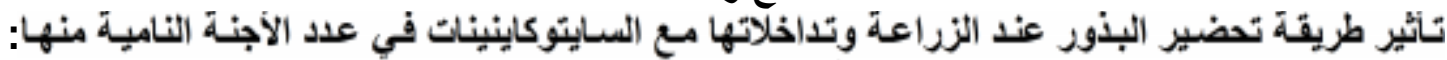

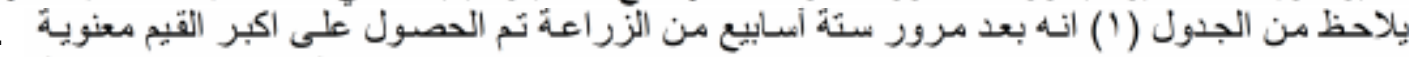

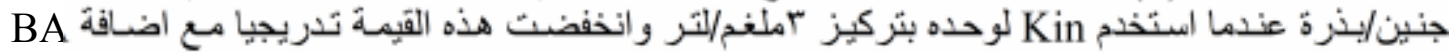

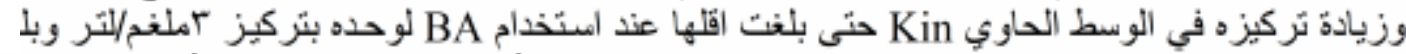

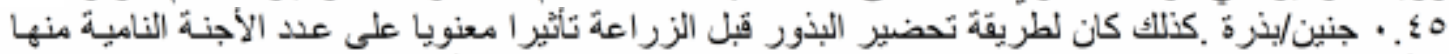

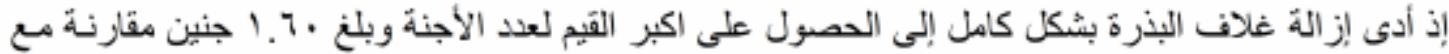

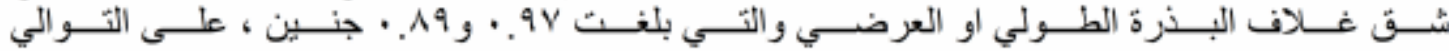

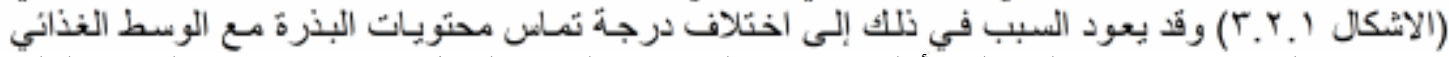

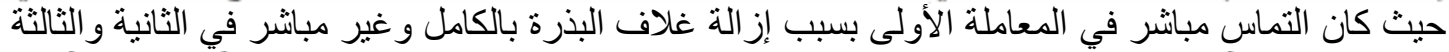

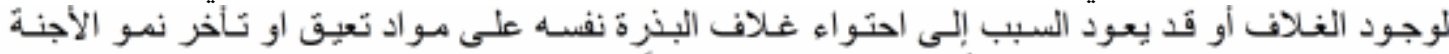

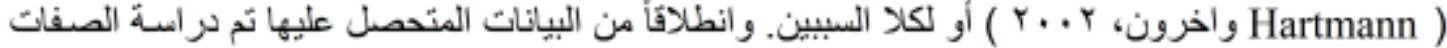
الاخرى على البذور التي ازيلت اغلفتها بالكامل.

MS الصـلب على عدد الأجنـة الناميـة مـن البذور Kin BA

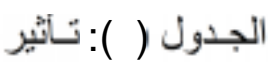

\begin{tabular}{|c|c|c|c|c|}
\hline \multirow[b]{3}{*}{$\mathrm{Kin}+\mathrm{BA}$} & \multicolumn{4}{|c|}{ بعد ستة أسابيع من الزر اعة } \\
\hline & \multicolumn{3}{|c|}{ معدل عدد الأجنة النامية / } & \multirow{2}{*}{$\begin{array}{c}\text { تركيز } \\
\text { Kin + BA } \\
/\end{array}$} \\
\hline & عرضياً & طولياً & & \\
\hline $\mathrm{bc}$ & . $\mathrm{dg}$ & . be & . $b c^{*}$ &..+ \\
\hline $\mathrm{a}$ & . $b c$ & $\mathrm{~b}$ & . $\mathrm{a}$ & + \\
\hline $\mathrm{b}$ & . $\mathrm{bd}$ & $\mathrm{bd}$ & $\mathrm{b}$ & + \\
\hline $\mathrm{c}$ & gi & $\mathrm{cf}$ & $\mathrm{bc}$ & + \\
\hline $\mathrm{d}$ & . gi & . gi & . bcs & + \\
\hline $\mathrm{d}$ & . eh & $\mathrm{i}$ & . $\mathrm{cf}$ & + \\
\hline $\mathrm{e}$ & . hi & $\mathrm{i}$ & . eh & + \\
\hline $\mathrm{e}$ & . $\mathrm{i}$ & $\mathrm{i}$ & . $\mathrm{fi}$ & + \\
\hline . & $\mathrm{b}$ & $\mathrm{b}$ & a & طريقة \\
\hline
\end{tabular}

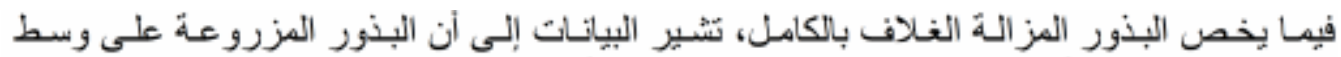

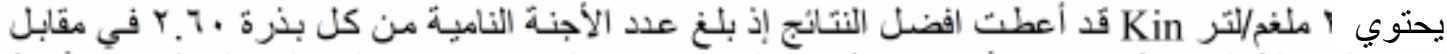

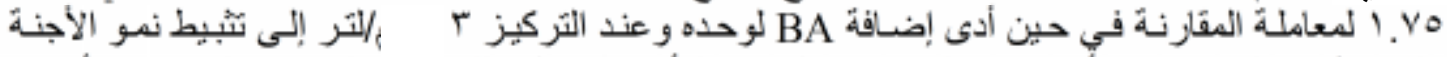

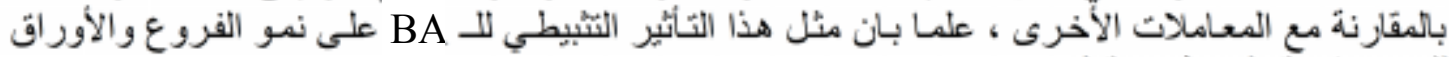

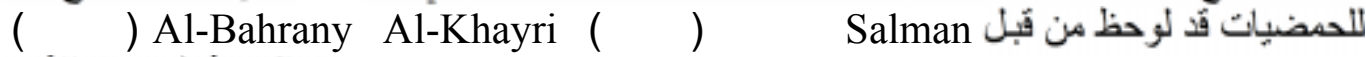

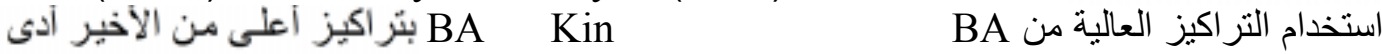

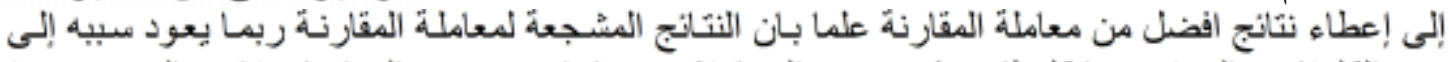

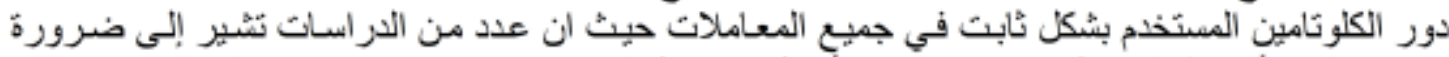

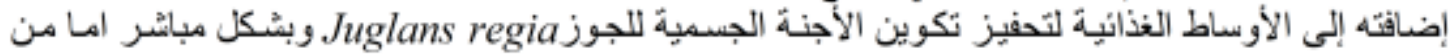
( Tulecke ) ( McGranahan Tulecke )

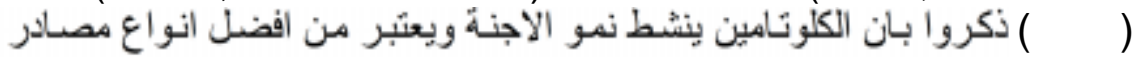

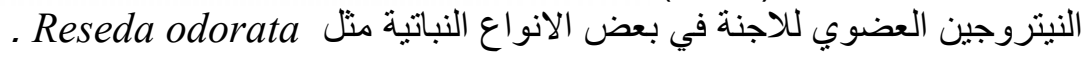




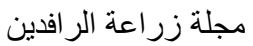

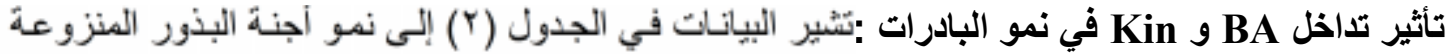

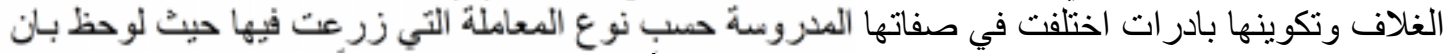

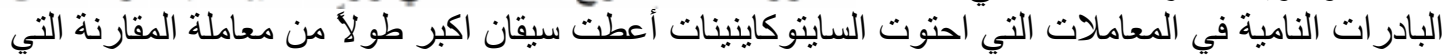

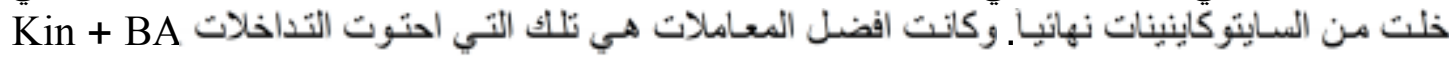

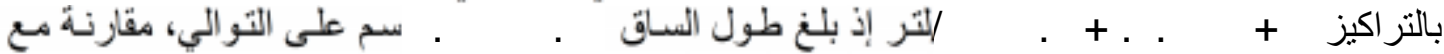

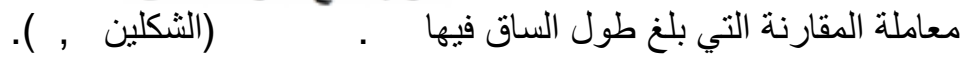

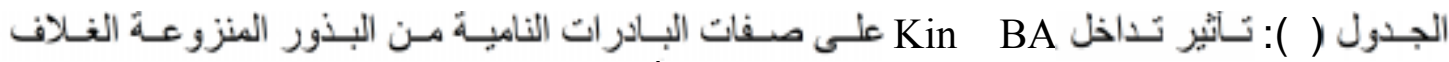

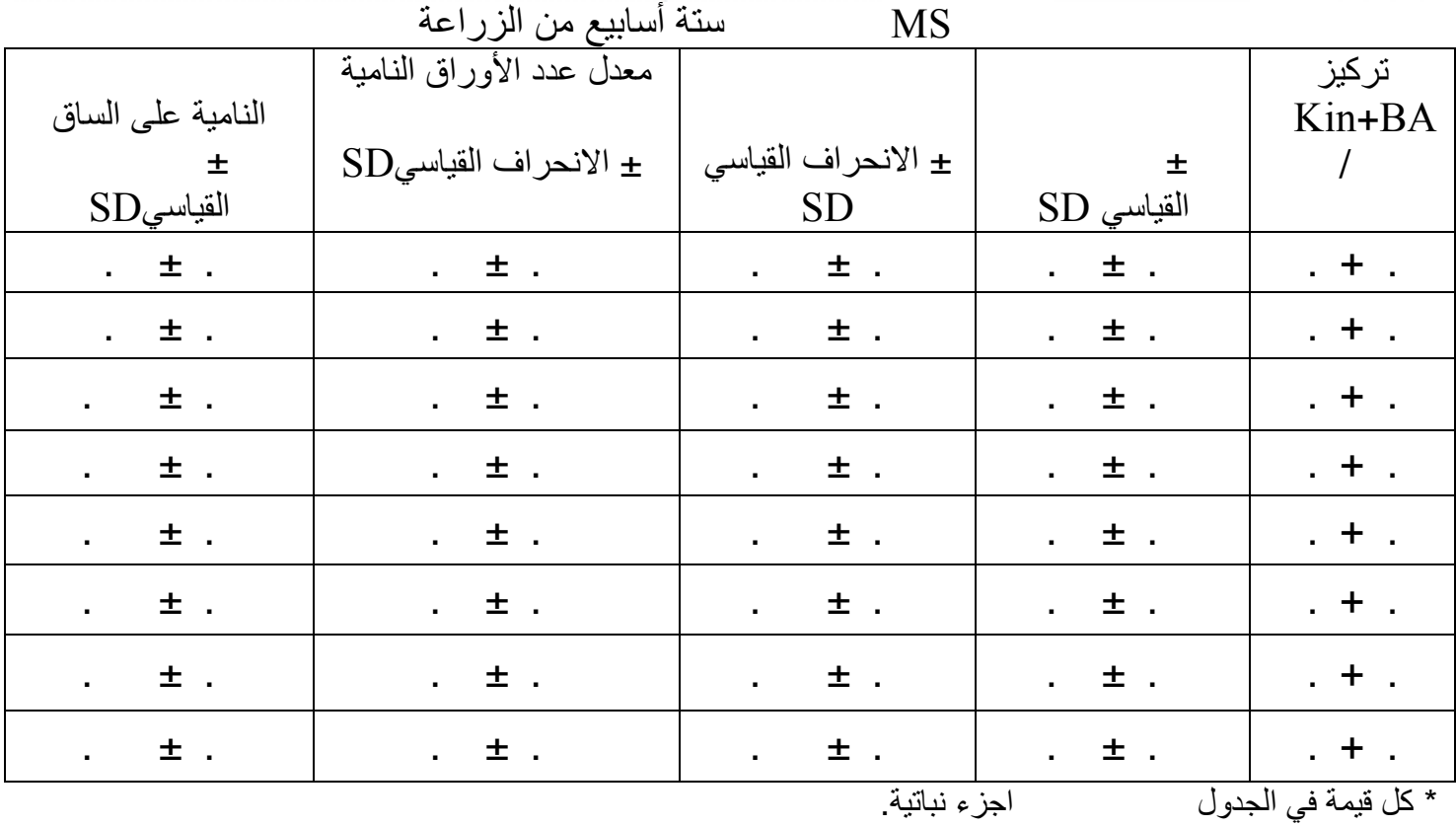

إن تأثثر

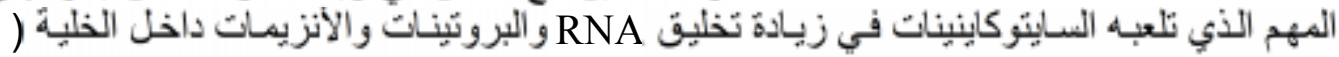

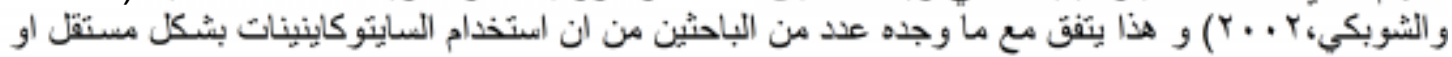

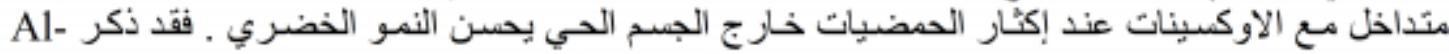

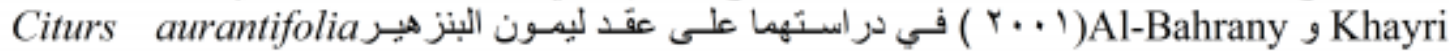

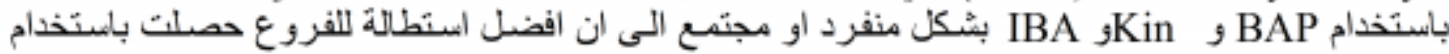

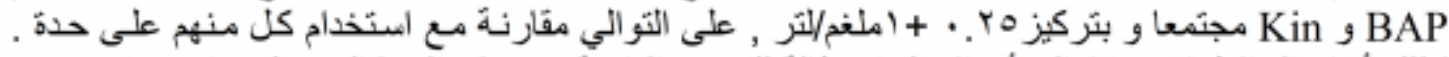

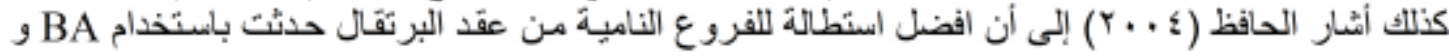

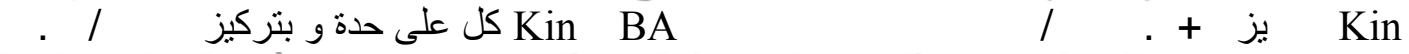

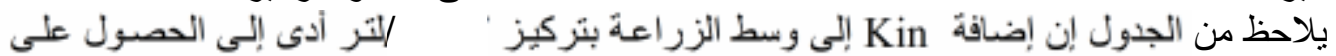

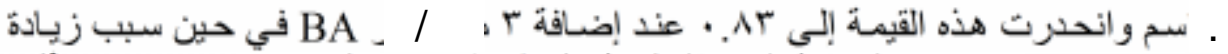

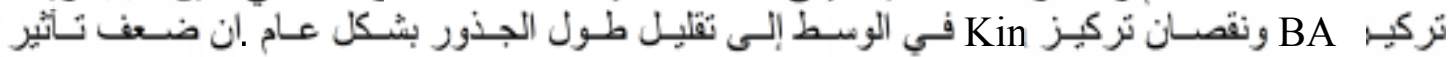

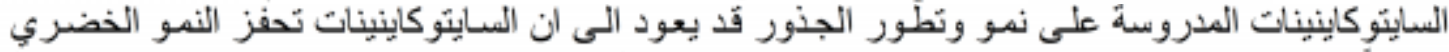

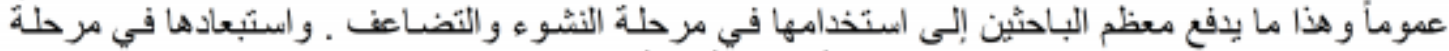

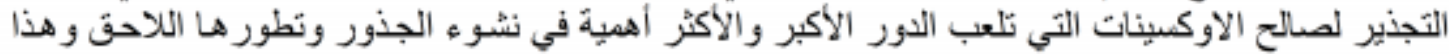

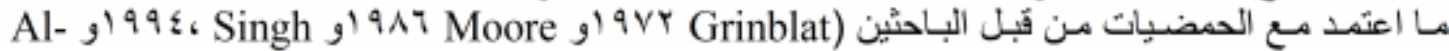
. Al-Bahrany Khayri

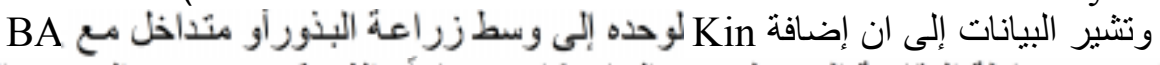

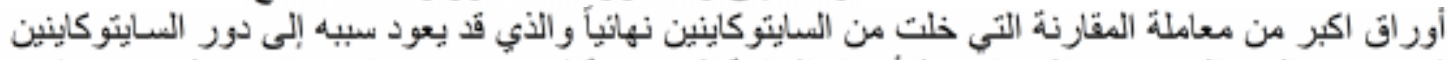

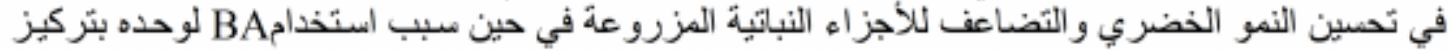



( ) ( )
(ISSN $1815-316$ X)
مجلة زر اعة الر افدين

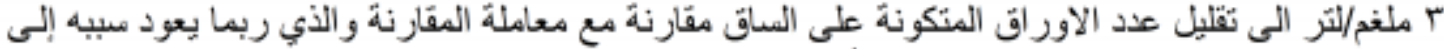

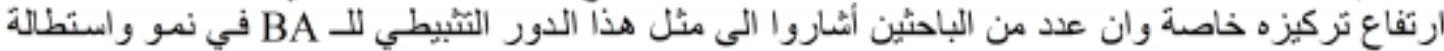

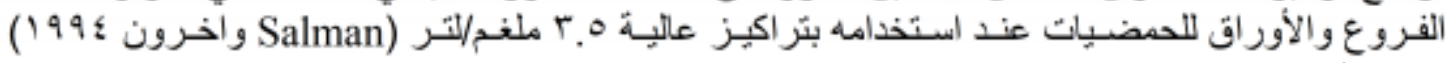

(Al-Bahrany Al-Khayri) /

كذلك اختلفت تُداخلات BA و Kin في قنرتها على تحفيز نمو البر اعم الابطية لمبقان البادر ات

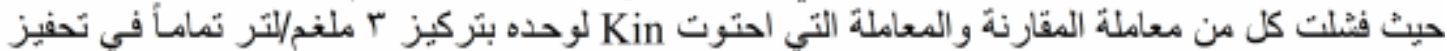

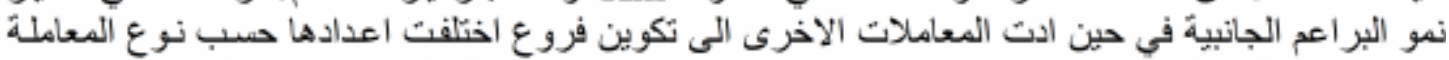

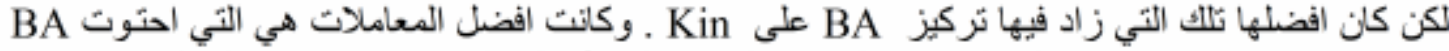
Kin +

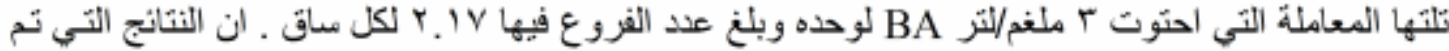

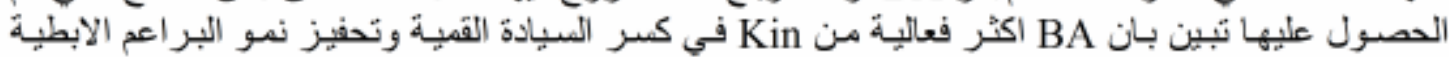

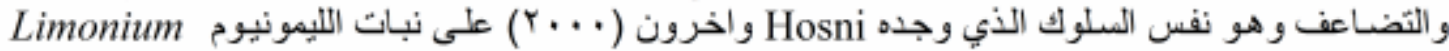
sinmuatum

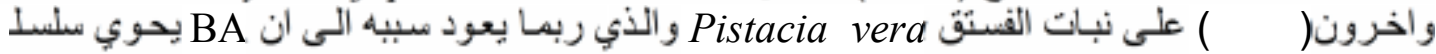

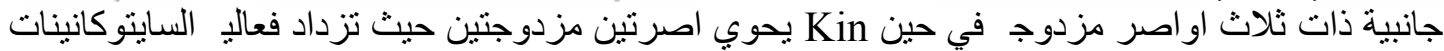

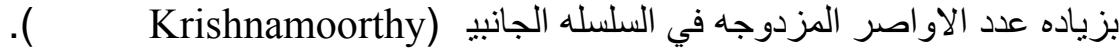
تاثير تداخل BA و Bin في نشوء البراعم العزضية: حدث تكوين بر اعم عزضية من البذور المنزوعة

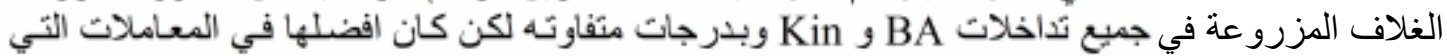
Kin + BA

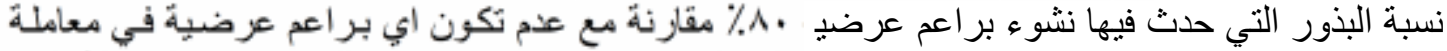
Kin BA

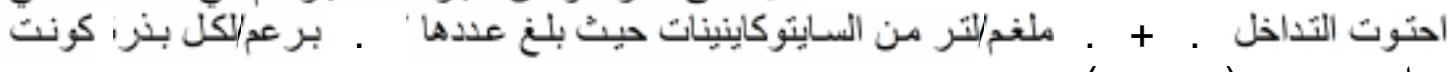

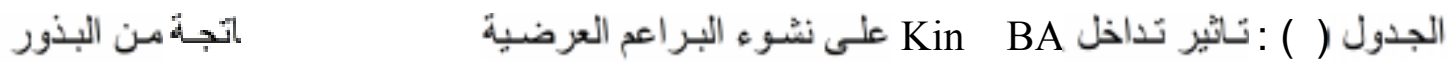
MS

\begin{tabular}{|c|c|c|c|}
\hline عدد البر اعم العرضية/ عرضي & بر اعم عرضي & عرضية & $\begin{array}{c}\text { تركيز } \\
\text { Kin + BA } \\
\text { / }\end{array}$ \\
\hline \pm & & & + \\
\hline. \pm & & & + \\
\hline .. \pm & & &.+ \\
\hline . \pm & & & + \\
\hline . \pm & & & + \\
\hline . $\quad \pm$ & & & + \\
\hline . \pm & & & + \\
\hline. \pm & & & + \\
\hline
\end{tabular}

ان فعالية السايتوكاينينات في احداث ونشو البر اعم وتضاعفها معروفة وقد استخدمت من قبل العديد

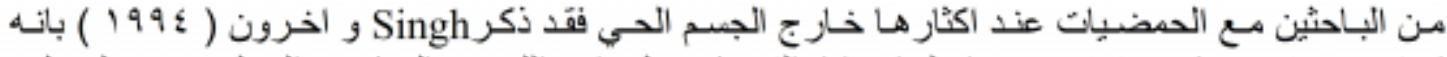

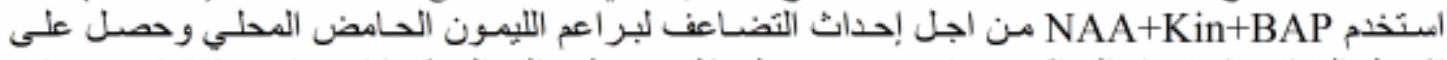

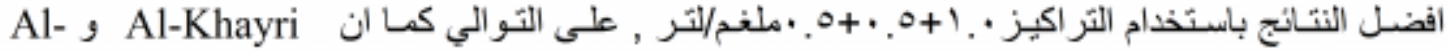

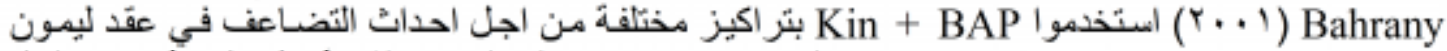

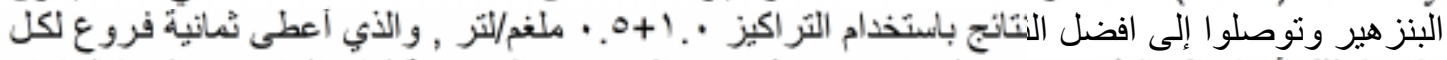

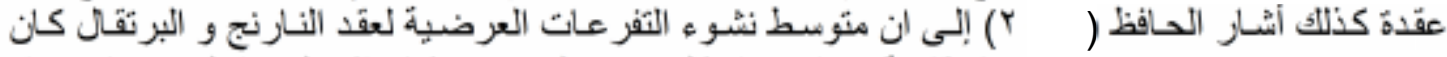

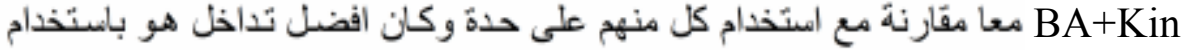




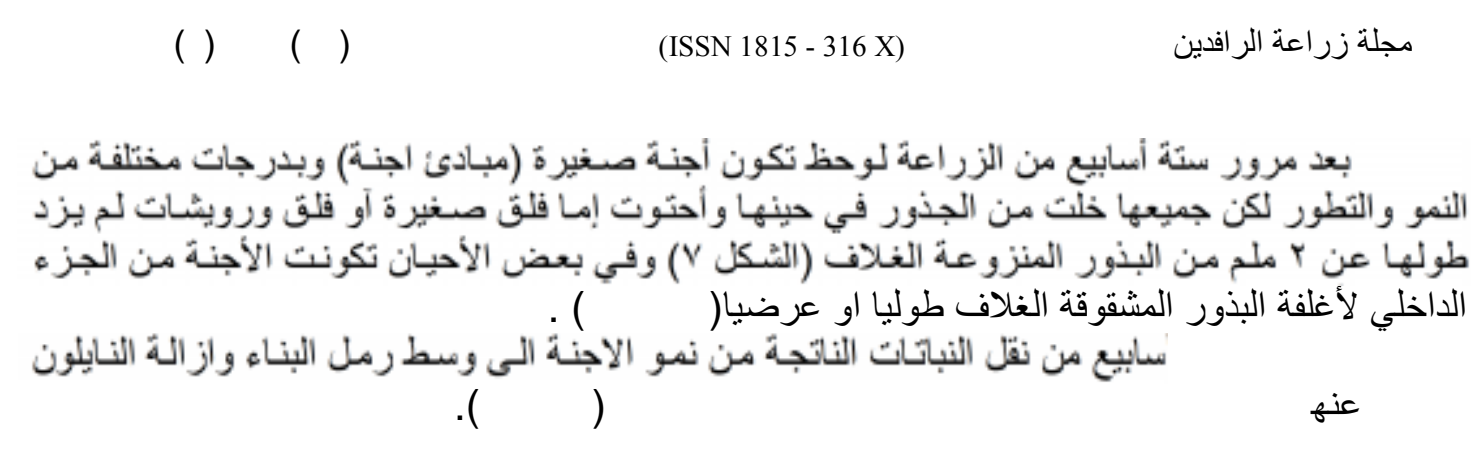

\title{
PROMOTION OF EMBRYOS GROWTH FOR IN VITRO CULTURED SEEDS OF LOCAL Citrus limon L. BRUM. F.
}

Ammar Zeki Kassab-Bashi

Hort. Dept., College of Agric. \& Forestry, Mosul Univ., Iraq.

\begin{abstract}
In this study seeds of local lemon were cultured in solidified Murashige and Skoog medium in order to examine the effect of combining Benzyladenine (BA) and Kinetin (Kin), in different concentration on the growth of embryos with / without seed coat. Favorable results were obtained after 6 weeks from seeds without seed coat comparably with seeds with seed coat, embryos growth from seeds without seed coat was in different degrees, were as, optimum results obtained in treatment containing Kin alone $3 \mathrm{mg} / \mathrm{L}$, average number of seedling from each seed 2.6 compared with 1.75 of control treatment (completely without cytokinins). The individual or combined use of BA and Kin caused increasing seedling steam length of seeds without seed coat compared with control treatment, while increasing root length when treated with Kin alone at concentration of $3 \mathrm{mg} / \mathrm{L}$. The subsequent use of BA and Kin at concentration of $2.5+0.5 \mathrm{mg} / \mathrm{L}$ caused elongation highest number of lateral buds of seedling which 2.29. When highest number of adventitious bud $(80 \%)$ occurred in treatment seeds without seed coat containing BA and Kin at concentration $1.5 \mathrm{mg} / \mathrm{L}$ for each one that was 2.13 buds from every seed.
\end{abstract}



( ) ( )

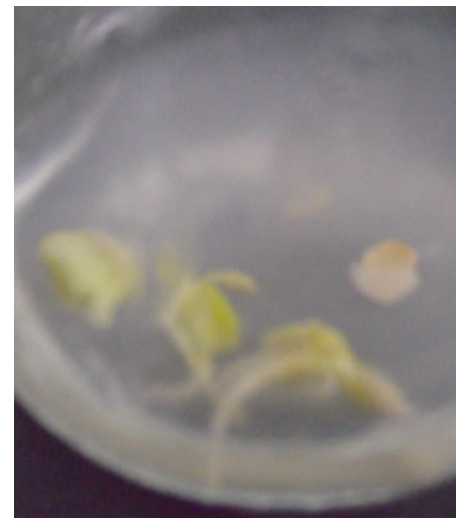

الثكل (r) بذور مشقوقة الغلاف

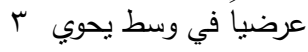

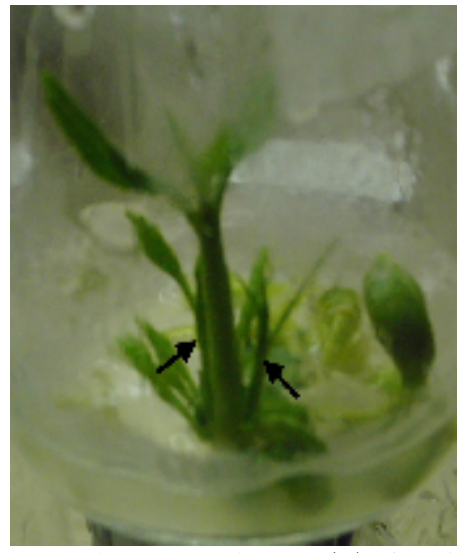

الثــكل (7) نمــو البـراعم الابطيــة

لساق البادرات في وسط يحوي BA Kin +

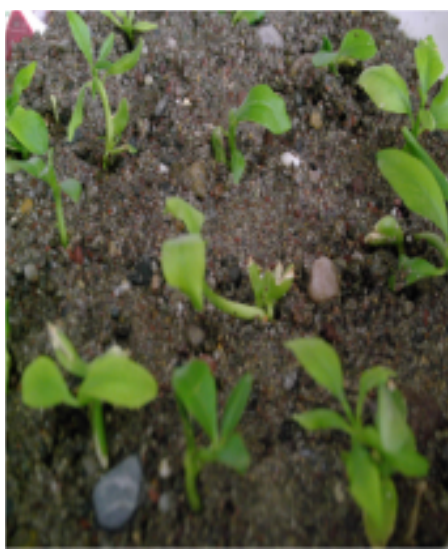

الثكل (9) نجاح نمو النباتات بعد النقل إلى رمل البناء

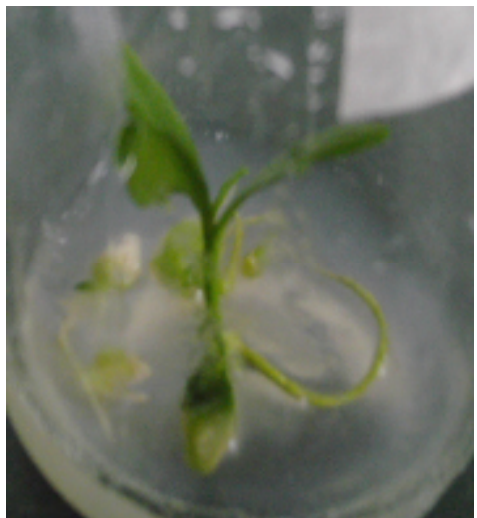

الثـكل(؟) بـــور مشـقوقة الغـلاف طوليا في وسط يحوي r ملغم/لتر Kin

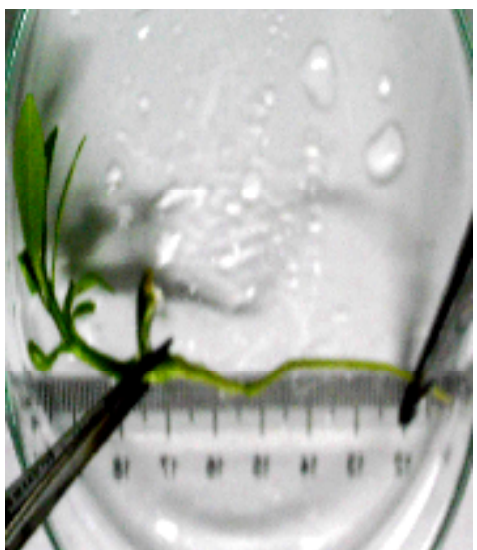

الثكل (0) نمو وتطور الأجنة إلى بادرات في وسط يحوي س ملغم/لتز Kin
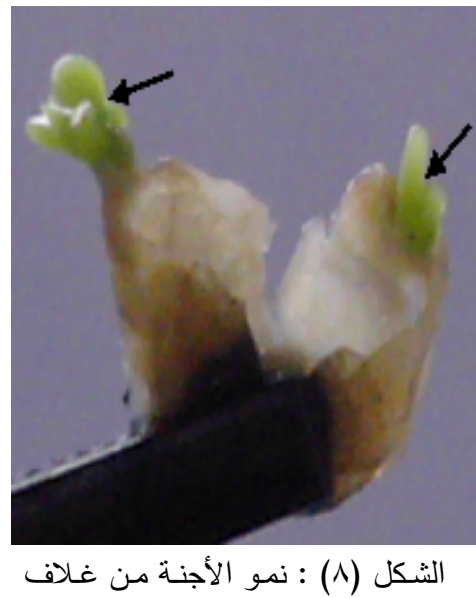

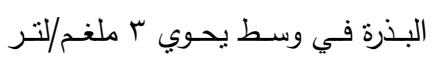

Kin

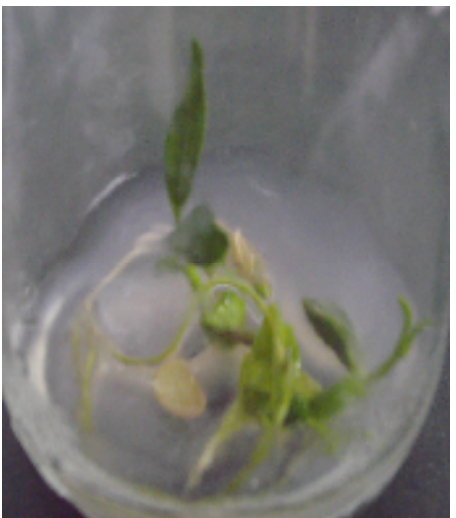

الثكل (1) بذور منزوعة الغلاف

بالكامل في وسط يحوي ب ملغف/لتر مin

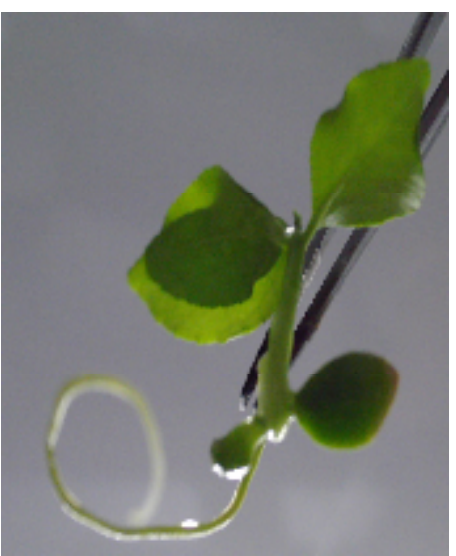

الثكل (£) نمو وتطور الأجنة إلى

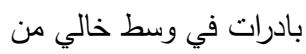
السايتوكاينيات

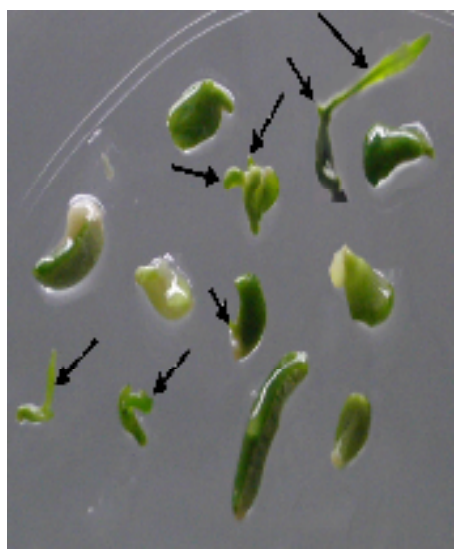

الثـكل (V) مبـادئ أجنـة في

Kin + BA وسـط يحسوي بتركيز 0. (ملغم/لتر لكل منهم

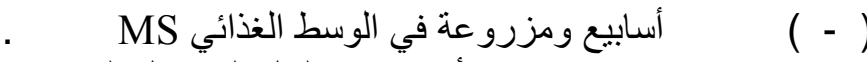
أسابيع من النقل الى رمل البناء. 


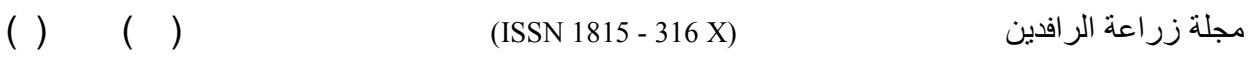

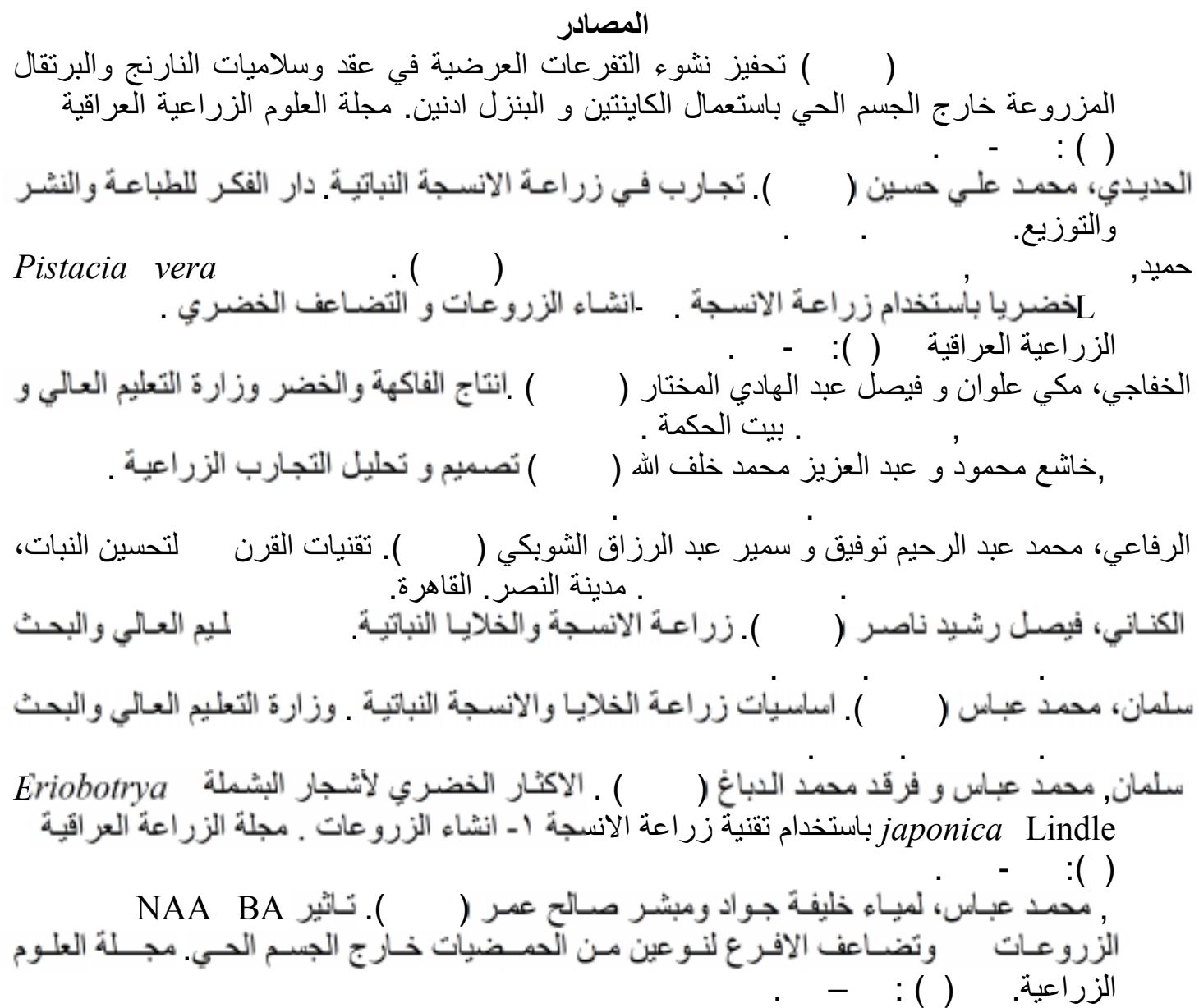

Al-Khayri, J. M. and A. M. Al- Bahrany (2001). In vitro micropropagation of Citrus aurantifolia (lime). Plant Tissue Cult. 12 (2) : 167-172.

Grinblat, U. (1972). Differentiation of Citrus stem In vitro. J. Amer. Soc. Hort. Sci. $97(5): 599-603$.

Grosser , J.W. and J.L. Chandler (1986) . In vitro multiplication of Swingle citrumelo rootstock with coumarin . HortScience . 21(3): 518-520.

Hartmann ,H. T., D. E. Kester, F. T. Davies , Jr, R. L. Geneve(2002). Plant Propagation Principles and Practices . 7th edition prentice Hall, Upper Saddle , New Jersey 07458 .

Hosni,A. M. ,Y.A.Hosni and M.A.Ebrahim (2000) In vitro micropropagation of Limonium sinnuatum "Citron Mountain" A hybrid statice newly introduced in Egypt. Annls Agric. Sci. 45(1):327-339.

Krishnamoorthy, H. N. (1981). Plant Growth substances Including Application in Agriculture. Tata McGraw Hill, New Delhi P:214

Miah, M. N., S. Islam and S. Hadiuzzaman (2002). Regeneration of plantlets through somatic embryogenesis from nucleus tissue of Citrus macroptera Mont. Var. anammensis (Sat kara). Plant Tissue Cult,. 12 (2): 167 - 172.

Moore, G. A. (1986). In vitro propagation of citrus rootstocks. HortScience 21 (2): $300-301$.

Murashige T.and F. Skoog (1962). A revised medium for rapid growth and bioassay with tissue culture. Physiologia Plantarum 15: 473 - 497. 


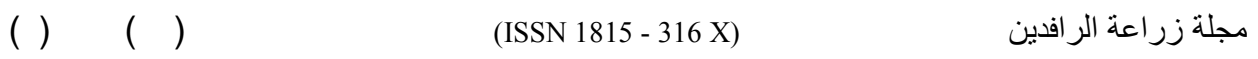

Navarro, L. (1984). Citrus tissue culture. In: Micropropagation of selected root Crops, Palms, Citrus and Ornamental species. FAO plant production and protection paper. $59: 155-176$.

Obukosia, S. D. and K. Watthaka (2000). Nucellar embryo culture of Citrus sinensis L. and Citrus limon L. African Crop Science J. 8 (2): 109 - 116.

Ranga Swamy, N.S. (1958). Culture of nucellar tissue of Citrus in vitro. Experieanta 14:11-12.

Ricci, A. P., F. A. Alves Mourao Filho, B. M. Januzzi mendes and S.M. Piedade (2002). Somatic embryogenesis in Citrus sinensis, C. reticulata and C. nobilis X C. deliciosa. Sci. Agric. (Piracicaba, Braz). 59 (1)

Salman, M. A., M. A. Hani. And S. M. Bader (1994). In vitro shoot multiplication of sour orange Citrus aurantium L. buds. The Iraqi J. of Agriculture Scinces 25 (1): $42-51$.

Singh, S., B. K. Rays, S. Bhattacharyya, and P. C. Deka (1994). In vitro propagation of Citrus reliculata Blanco and Citrus limon Burm f.HortScience. 29(3):214-216.

Tulecke, W.and G. McGranahan (1985) .Somatic embryogenesis and plant regeneration from cotyledons of walnut, Juglans regria L. Plant Science, 40:57-63 .

Tulecke, W., G.McGranahan, H. Ahmade (1988) Regeneration by somatic embryogenesis of triploid plants from endosperm of walnut, Juglans regia L. cv Manregian. Plant Cell Reports 7:301-304 . 